\section{Brustkrebsspezifische DNA-Spuren im Blut}

Beim metastasierten Mammakarzinom ist die Kontrolle der Tumorlast wichtig, um das Therapieansprechen zu beurteilen. Als neuer Biomarker könnte dabei tumorspezifische zirkulierende DNA helfen.

$\mathrm{D}$ ie bisher untersuchten Biomarker im Blut, das Krebsantigen 15-3 (CA 153) und zirkulierende Tumorzellen, sind noch nicht ausreichend sensitiv. In der zellfreien Fraktion in sehr geringen Mengen vorkommende zirkulierende DNA mit tumorspezifischen Veränderungen könnte dies verbessern. In einer Proofof-Concept-Studie verglich man die radiologisch ermittelte Tumorlast von 30 Patientinnen mit metastasiertem Mammakarzinom im Laufe einer systemischen Therapie mit dem Verlauf von zirkulierender Tumor-DNA, CA 15-3 und zirkulierenden Tumorzellen. Zur Detektion von zirkulierender Tumor-DNA wurde zunächst gezielt nach Mutationen im PIK3CA- und im TP53-Gen gesucht und dann mittels digitaler PolymeraseKettenreaktion (PCR) und tiefer Amplicon-Sequenzierung das ganze Genom nach somatischen Genmutationen untersucht. Auf diese Weise konnte bei 29 von 30 Frauen (97\%) zirkulierende TumorDNA mit somatischen Mutationen identifiziert werden. CA 15-3 war bei 27 Frauen nachweisbar und konnte in 21 Fällen $(78 \%)$ kontinuierlich verfolgt werden. Zirkulierende Tumorzellen bei 26 der 30

Im Verlauf zeigten die Werte der zirkulierenden Tumor-DNA eine größere Dynamik und eine bessere Korrelation zu Veränderungen der Tumorlast als die anderen beiden Biomarker. Bei 10 von 19 Frauen (53\%) mit Therapieansprechen Frauen (87\%). zeigten sie als erstes im Blut das Ansprechen an - im Mittel fünf Monate vor der Bildgebung. Bei zwei Frauen war trotz eines Biomarkeranstiegs allerdings im CT keine Progression nachweisbar.

Zirkulierende Tumor-DNA war in dieser kleinen Studie auch prognostisch relevant - eine Erhöhung der Werte war signifikant mit einem schlechteren Gesamtüberleben assoziiert $(p<0,001)$, ebenso ein Anstieg der zirkulierenden Tumorzellen $(p=0,03)$, nicht aber der CA-15-3-Werte.

Fazit: Chance und Problem der Methode zugleich ist die Personalisierung: Sie ist teuer. Die Studie belegt aber, dass der personalisierte Test auf zirkulierende Tumor-DNA möglich ist und spezifischer und sensitiver zu sein scheint als bisherige Marker.

Friederike Klein

Dawson SJ et al. Analysis of circulating tumor DNA to monitor metastatic breast cancer. N Eng J Med. 2013;368(13):1199-209.

\title{
Bewegungseffekt bei Brustkrebs auch vom Hormonrezeptorstatus abhängig
}

Frauen, die körperlich aktiv sind, haben ein verringertes Brustkrebsrisiko. Ob der Hormonrezeptorstatus eine Rolle spielt, ist bisher nicht eindeutig geklärt.

m Rahmen der prospektiven EPIC-Studie (European Prospective Investigation into Cancer and Nutrition) zum Einfluss von Lebensstil-Faktoren auf Krebsrisiken wurde jetzt an einer großen Kohorte untersucht, ob die Expression von Östrogen- und/oder Progesteronrezeptor (ER, PR) den günstigen Effekt von Bewegung auf das Krebsrisiko beeinflusst. Für alle Frauen lagen detaillierte Informationen zum Bewegungsverhalten - beruflich, im Haushalt und in der Freizeit - vor. Binnen median 11,6 Jahren wurden bei 8.034 von 257.805 Frauen invasive Mammakarzinome diagnostiziert. Für 6.007 Karzinome war der ERStatus bekannt, für 4.814 der PR-Status und für 4.798 beides.

Das Brustkrebsrisiko war umso geringer, je mehr die Frauen körperlich aktiv waren. Bei der Auswertung in Quartilen ergab sich für moderate Aktivität ein um
$8 \%$ reduziertes Risiko (Hazard Ratio [HR] 0,92, 95\%-Konfidenzintervall [95\%-KI] 0,86-0,99), bei hoher körperlicher Aktivität verringerte es sich um $13 \%$ gegenüber nicht oder wenig aktiven Frauen (HR 0,87, $95 \%$-KI 0,79-0,97; p für Trend $=0,002)$. Allerdings gab es Unterschiede: Die Gesamtaktivität war etwas stärker invers korreliert mit zweifach rezeptorpositiven Mammakarzinomen $(\mathrm{ER}+/ \mathrm{PR}+)$, wobei dies vor allem auf PR-positive Tumoren zurückging. Die Bewegung im Haushalt korreliert dagegen invers mit zweifach rezeptornegativen Tumoren (ER-/PR-).

Fazit: Die bisher größte prospektive Studie dieser Art bestätigt einen mäßigen präventiven Effekt moderater bis ausgeprägter körperlicher Aktivität auf das Brustkrebsrisiko. Die unterschiedlichen Effekte bezüglich des Rezeptorstatus las-

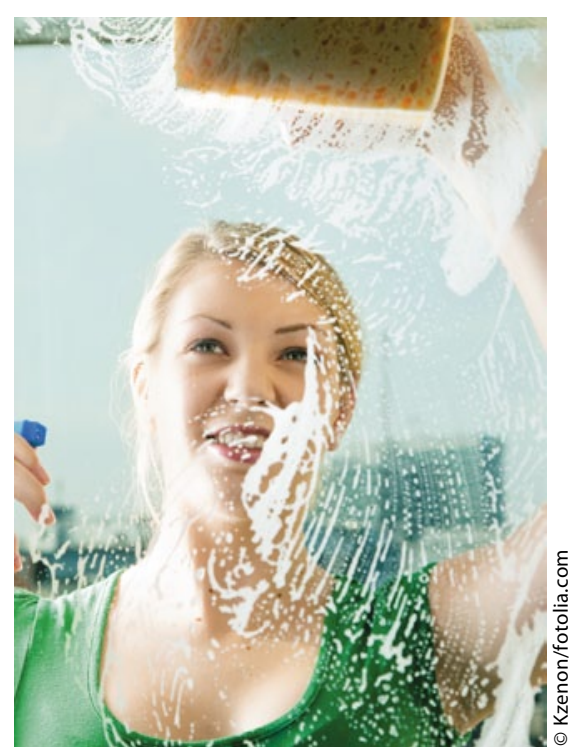

Auch diese Form der Bewegung scheint das Brustkrebsrisiko zu senken.

sen auf einen hormonabhängigen Einfluss schließen.

Friederike Klein

Steindorf K et al. Physical activity and risk of breast cancer overall and by hormone receptor status: The European Prospective Investigation into Cancer and Nutrition. Int J Cancer. 2013;132(7):1667-78. 